\title{
THE DOUBLE-EDGED SWORD OF RP: THE CONTRASTING ROLES OF A PRONUNCIATION MODEL IN BOTH NATIVE AND NON-NATIVE ENVIRONMENTS
}

\author{
MIROSLAV JEŽEK \\ Masaryk University, Brno
}

\begin{abstract}
Received Pronunciation (RP) is often studied as the pronunciation model in Great Britain and non-English-speaking countries separately. What my paper focuses on is the duality with which RP is essentially endowed: the role(s) in which it has to satisfy the needs of both native and non-native speakers of English.

Whilst the claim that RP has changed recently goes unchallenged, the issue of reflecting these changes in the preferred transcription models is hotly debated. Upton's model of RP is one that does include several new symbols, motivated by an attempt to 'ensure that the description of a late twentieth century version the accent $[\ldots]$ looks forward to the new millennium rather than back at increasingly outmoded forms' (2001:352). I discuss the feasibility of adopting Upton's model of RP as the pronunciation model in non-English speaking countries, where it is desirable to resolve the paradox that 'most of our teaching is aimed at young people, but the model we provide is that of middle-aged or old speakers' (Roach 2005: 394).

The observations I make are largely based on my MA research, which is now being modified for the purposes of my Ph.D. I asked undergraduate students of English in England and the Czech Republic to evaluate seven voices ranging from the clearly regional to the unquestionably RP. The objective was to discover which sounds are considered to fall within the scope of RP by students in both countries, which approach avoids treating RP as though it were to include only the sounds 'allowed by a preconceived model' (Upton 2000: 78). Further, the respondents were asked to comment on the most salient features in the recordings: what they opted to comment on reveals a marked difference in the role of RP as a model accent in the given countries. Societies which lack a prestigious non-regional accent are often oblivious to the social connotations RP carries. Whilst it seems technically impossible to replace the model accent in all teaching materials all over the world, creating awareness of the fact that a rather outmoded model of RP found in many textbooks may not always be the best option is a necessary step towards ensuring that non-English speaking students are not only understood but that their speech will attract no adverse judgements.
\end{abstract}

\section{Introduction}

$\mathrm{RP}$, like any other accent, is subject to constant change. However, the transcription model found in materials for ELT purposes has changed little since Jones's transcription, first used in the English Pronouncing Dictionary published in 1917. The reasons are manifold. Upton (2001: 355) mentions the following as the most prominent ones: 
- in the world of lexicography, phonological matters are not usually given priority (this is presumably brought about by the fact that most lexicographers are not phoneticians, hence they do not pay as much attention to the matters of pronunciation as they do to semantics and grammar)

- there is strong conservative pressure in the ELT divisions of publishing houses

- phonological redescription in ELT dictionaries would also entail the revision of a great number of other non-dictionary texts in which pronunciation is discussed this would be rather impractical and, above all, too costly

For the aforementioned reasons it might seem to an outsider (in particular to someone who does not reside in the UK and whose first language is not English) that RP is an accent with little, if any, variation. The best testimony to prove that the opposite is true is the number of labels often attached to RP. The basic division phoneticians make is into an older, rather conservative, variety and a younger, modern one. The former is labelled 'traditional RP' (Upton 2008: 239), 'U-RP' (Wells 1982: 279), 'Refined RP' (Cruttended 1994: 80) or 'marked RP' (Honey 1991: 38). The latter is called 'mainstream RP' (Wells 1982: 279), 'General RP' (Cruttended 1994: 80), 'unmarked RP' (Honey 1991: 38), or there might not be any label at all: Upton (2000: 76) decided to call this modern variety simply 'RP' on the grounds that it is the mainstream variety and it can therefore 'legitimately lay claim to the RP label without qualification'.

$\mathrm{RP}$ is an accent endowed with both advantages and disadvantages. This has been well-documented in a wealth of research; cf. for example Giles (1990) and, more recently, Beal (2008). RP is viewed as competent, persuasive and intelligent, but, at the same time, as rather unfriendly and dishonest (Beal 2008: 29). This is the reason why I call RP a 'double-edged sword': it may open some doors for you but it may also close others.

Prof. Clive Upton, currently based at Leeds University, is the only linguist who has radically altered the transcription model of RP with the aim of providing a transcription model which avoids 'slavish imitation of the dictates of self-appointed arbiters of taste or style in language' (Upton 2003: viii). Instead, Upton only includes those sounds 'heard to be used by educated, non-regionally marked speakers rather than [sounds] "allowed" by a preconceived model' (Upton 2000: 78). Ramsaran shrewdly observes that '[i]f one excludes certain non-traditional forms from one's data, how can one discover the ways in which the accent is changing?'. In other words, one cannot use the same sieve, metaphorically speaking, over and over again to see who falls through and who does not. This is hardly a successful way of detecting linguistic change.

It is now time to turn our attention to the actual description of the model in question.

\section{Upton's model of RP}

Upton's model has been in use for about two decades now and the most notable publications where this model can be found include the world-famous Oxford English Dictionary (OED). Other dictionaries using Upton's model of RP are, for example, The New Shorter Oxford English Dictionary (from 1993 onwards), The Concise Oxford Dictionary (from 1995 onwards), and The New Oxford Dictionary of English (1998, 
2003). Last but not least, The Oxford Dictionary of Pronunciation for Current English (2001) is also on the list, this being the only dictionary focusing solely on pronunciation.

The call for an updated version of the RP model had been around for some time before Upton decided to undertake the task of providing one. Gimson, in particular, insisted that a new set of criteria for redefining RP be found. These 'will result in a somewhat diluted form of the traditional standard' (1984: 53). In the same article Gimson adds his hope that

the re-defined RP may be expected to fulfil a new and more extensive role in present-day British society. Its primary function will be that of the most widely understood and generally acceptable form of speech within Britain [...] and more importantly for the future, this standard form of British speech can function as one of the principal models for users of English throughout the world

(1984: 53)

\subsection{RP Vowels}

While most of the vowels employed by Upton are the same as in other (older) models of $\mathrm{RP}$, there are several salient changes which have made his model a contentious issue. The following table taken from Upton (2008: 241-2) neatly summarises the differences between RP and traditional RP:

\begin{tabular}{|c|c|c|c|}
\hline vowel & RP & shared RP/trad-RP & trad-RP \\
\hline KIT & & I & \\
\hline DRESS & $\varepsilon$ & & e \\
\hline TRAP & $a$ & & $æ$ \\
\hline LOT & & $\mathrm{D}$ & \\
\hline STRUT & & $\Lambda$ & \\
\hline FOOT & & $U$ & \\
\hline BATH & $a: \sim a$ & & a: \\
\hline CLOTH & $\mathrm{D}$ & & $\mathrm{D} \sim \mathrm{O}:$ \\
\hline NURSE & $\partial:$ & & 3: \\
\hline FLEECE & & i: & \\
\hline FACE & & eI & \\
\hline PALM & & $a:$ & \\
\hline THOUGHT & & $0:$ & \\
\hline GOAT & əU & & $\partial U \sim O U$ \\
\hline GOOSE & & u: & \\
\hline PRICE & $\Lambda \mathrm{I}$ & & aI \\
\hline CHOICE & & OI & \\
\hline MOUTH & & au & \\
\hline NEAR & & Iə & \\
\hline SQUARE & $\varepsilon:$ & & $\varepsilon \partial$ \\
\hline START & & $a:$ & \\
\hline
\end{tabular}




\begin{tabular}{|l|l|l|l|}
\hline vowel & RP & shared RP/trad-RP & trad-RP \\
\hline NORTH & & ว: & \\
\hline FORCE & & 0: & \\
\hline CURE & Uə $\sim$ ว: & & Uə \\
\hline happY & & $\mathrm{i}$ & \\
\hline lettER & & ə & \\
\hline commA & & ə & \\
\hline
\end{tabular}

Table 1: The vowels of RP and traditional RP (Upton 2008: 241-2)

Whilst some changes seem to be mere transcriptional preferences (e.g. DRESS or NURSE), others have raised a few eyebrows because they essentially alter the way RP is perceived and interpreted. Namely it is the TRAP, BATH and PRICE lexical sets that are discussed here in detail.

Firstly, the TRAP vowel is lowered so that the appropriate symbol is no longer the ash symbol [æ], but the cardinal vowel no. 4 [a]. Wells (2001) insists that it is not necessary to make the change as it is enough to retain the original symbol and simply redefine it. This is, however, hardly possible due to the fact that phonetic symbols are absolutes, therefore 'their interpretation cannot be altered to suit the new development, so that if anything is to change in the interests of accuracy and clarity it must be the label that is applied to the sound' (Upton 2008: 240). Upton goes on to argue that because ELT texts are broadly phonemic 'their users [...] need to be provided with transcriptions which correspond as honestly as possible to the sounds of the modern accent' (2008: 240).

Secondly, Upton introduces the short BATH vowel [a], typically associated with the North of England, as a possible RP alternative to the usual long BATH [a:]. The logic behind this decision is relatively simple: people in the North of England no longer adopt the southern long BATH vowel; as a result even those who would normally be perfect RP speakers cannot be labelled thus because they retain the short BATH vowel. If the older model is taken as the norm, there is not (or soon will not be) a single RP speaker in the North and, more importantly, RP ceases to be a non-regional accent. Instead, it is immediately associated with the South of England. Upton then introduces 'southern' and 'northern' varieties of RP, thereby adhering to the universally accepted principle that ' $R P$ is not to be considered as exclusively a southern-British phenomenon' (Upton et al. 2003: xiii).

Thirdly, the PRICE diphthong, changed from trad-RP [aI] to RP $[\wedge \mathrm{I}]$ has come in for a significant amount of criticism. Wells (2001) admits that there is a lot of variation in the starting point of the diphthong but strictly dismisses Upton's choice as 'very unsuitable [because it] accords with the habits neither of RP nor of southeastern speech'. It is interesting to ponder a little on why the second element (south-eastern speech) is added in the previous quote from Wells. I understand why Wells is unhappy about Upton's choice of $[\Lambda \mathrm{I}]$ if he cannot see it used in RP at all, but adding that it is not present in south-eastern speech either seems to go against the criterion that RP should not be associated with any particular region. Incidentally, this is exactly the reason why 
Upton's model of RP comes in for a lot of criticism - his inclusion of the short BATH allegedly deprives RP of its non-regional basis. Surely, RP should only allow-where possible, of course - supraregional sounds not associated with any particular region. One notable exception is the short/long BATH vowel, where both regions stick to their own varieties. A linguist can then either dismiss one of the two variants as non-standard or allow both in their model of standard pronunciation.

This idea is far from modern: in 1942 Vilem Mathesius, the founding father of English Studies in Czechoslovakia, observed that people from the Bohemia region (centred on Prague) pronounce the initial consonant cluster in the Czech word 'shoda' (Eng. 'agreement') voicelessly while people in the Moravian region (centred on Brno) prefer the voiced variant. Although the former, i.e. voiceless, pronunciation had traditionally been regarded as standard, Mathesius noticed that people from Moravia, though otherwise perfectly conforming to the standard-speaker model, stick to the voiced variant. In a dilemma very similar to the one Upton found himself in, Mathesius opts to accept both variants as standard (1982: 149).

\subsection{RP Consonants}

RP consonants are nowhere near as variable as its vowels; hence they pose considerably fewer problems for phoneticians. Many variants found in Upton's model are RP universals and are thus not unique to his model. The only consonantal feature worth mentioning here is the presence of optional intrusive /r/, as in 'drawing' [dro:(r)ID]. The italics mean that the $/ \mathrm{r}$ / sound is intrusive rather than linking, which is shown in normal font.

\section{Research}

I conducted the research in 2009 for the purposes of my MA thesis. Right now, it is being modified and, hopefully, improved at Ph.D. level. The whole idea formed in my mind during my year-long stay at Leeds University in 2006-2007. It was not until then that I started to realise certain differences in the perception of RP in the UK and the Czech Rep.

\subsection{Research objectives}

- to compare the roles RP fulfils in the UK and the Czech Rep.

- to test the extent to which undergraduate students of English in both countries are aware of recent innovations in RP

- to discover which sounds are considered to fall within the scope of RP by students in both countries 


\subsection{Methodology}

I set up a simple website which can still be accessed here: www.received pronunciation.wz.cz. I asked respondents from both the UK and the Czech Rep. to evaluate seven recordings which ranged from clearly non-RP/regional to trad-RP. All the UK respondents were, incidentally, English (although I would certainly not have discarded data from, say, Scottish or Welsh people). They were all aged 19-25 and were either of working or of middle-class background. They were from all sorts of regions within England - if we take into account the two best-known criteria which separate the North from the South (namely the BATH and STRUT vowels), then I can say I had 17 southern and 13 northern respondents. The Czech respondents were also aged 19-25; furthermore, I chose only those who model their speech the British way. Five of the seven recordings were made by me; the remaining two (including the trad-RP recording) were taken from Collins et Mees (2003). Each recording was accompanied by a questionnaire. First, the respondents were asked to indicate, on a scale of 1 to 7 (1-highly regional, 7-RP), how close to RP the given recording sounded to them. I view RP, like any other accent, quantitatively (more or less) rather than qualitatively (either...or). This is something foreign students often seem oblivious to: they think that someone either speaks RP or they do not. But this is utterly mistaken as Wells' category of Near-RP (Wells 1982: 279) testifies. Then they went on to fill in several write-in questions. I deemed it extremely important not to ask about any particular sounds so as not to put ideas into my respondents' minds. The questions were thus rather vague such as 'What is your overall impression of this speaker?' or 'Can you comment on any particular details which helped you make up your mind in the RP score question?'. What the respondents opted to comment on - regardless of whether their comments were positive or negative - reveals a marked difference in the role of RP as a model accent in the given countries.

\section{Results}

It is perhaps not surprising that what I ended up with was just a hotchpotch of comments which were then classified into categories by the common topic. The most salient categories include the following: intelligibility, regionality, social status, education, poshness. There were admittedly some more categories, namely euphony, speed, authenticity, appropriateness, and rhythmicality, but these were found rather awkward to deal with or useless and will not be taken into account in the Ph.D. research.

A very simple table below illustrates the differences between $\mathrm{GB}$ and $\mathrm{CZ}$ respondents:

\begin{tabular}{|c|c|c|}
\hline CATEGORY & GB respondents & CZ respondents \\
\hline Intelligibility & 3 & 26 \\
\hline Regionality & 37 & 9 \\
\hline Social status & 14 & 3 \\
\hline Education & 12 & 6 \\
\hline Poshness & 11 & 4 \\
\hline
\end{tabular}

Table 2: observations by topic (measured in index points) 
What is immediately observable is the fact that for Czech learners of English the crucial aspect when they assess English speakers is intelligibility. The remaining four categories are not nearly as important for them as they are for their British counterparts. This is obviously perfectly understandable and entirely predictable, but it shows without any doubt that the roles of RP in native and non-native environments are markedly different and should therefore be kept separate whenever transcription models are discussed.

Czech university students of English are, of course, told about the regional and social connotations RP carries but I argue there is a huge gap between knowing something and feeling it intuitively. Czech learners of English often see RP as the most intelligible accent and thus consent to learn it almost automatically. Unfortunately, the model of RP they find in teaching materials is outdated, which is rather startling, for the recordings found in the very same textbooks often do not correspond with the transcripts. One could argue that these recordings are not then RP (and unquestionably many of them really are not), but it would then mean that there are no RP recordings in modern textbooks of English. The next question then suggests itself: Why are these teaching materials full of phonetic transcriptions of an accent which does not appear in them at all?

The TRAP vowel is a case in point. While the transcriptions invariably insist on [æ], the recordings include voices with lowered [æ] for which it seems more appropriate to choose [a]. Specifically, I am now talking about Maturita Solutions textbooks used mainly in secondary schools - there are several pronunciation exercises which stress the importance of distinguishing such minimal pairs as 'pat' [pæt] and 'pet' [pet]. Sadly, the TRAP vowel is predominantly realised as [a] in the recordings (this might be so because of the fact that the majority of the voices, without any doubt, belong to people in their twenties, if not younger, which in itself is a very welcome step, of course). It then takes me a lot of time explaining to my students that there is no need to attempt [æ] and that [a] is perfectly acceptable. For many Czech learners of English, the adoption of [a] would certainly help to make the situation easier since they have [a], unlike [æ], in their repertoires.

The question in which respondents were asked to evaluate the recordings on a scale of 1 to 7 (1-highly regional, 7-RP) provided some intensely interesting data as well. Three speakers' scores are worth looking at in greater detail.

\begin{tabular}{|l|l|l|}
\hline SPEAKER & GB respondents & CZ respondents \\
\hline Speaker 3 (most regional) & 2.7 & 3.45 \\
\hline Speaker 4 (modern RP) & 5.1 & 3.45 \\
\hline Speaker 6 (trad-RP) & 6.3 & 5 \\
\hline
\end{tabular}

Table 3: RP scores for three selected speakers

I have decided to retain the original numbers the speakers had been assigned in the RP Test in order that the readers could visit the website and listen to the recordings for themselves.

As we can see, the most regional Speaker 3 (the accent is, by the way, not a particularly strong one, the voice belongs to a Ph.D. student of the English language from Middlesbrough) received exactly the same score from Czech respondents as modern-RP Speaker 4 did. There are two possible explanations: either students in the 
Czech Republic failed to spot those regional features which clearly are not RP (e.g. lowered STRUT and monophthongised GOAT) or their perception of RP is rather outdated and what is considered modern RP now in the UK is still perceived as non-RP in the Czech Republic. The latter explanation, however, is made somewhat doubtful in the light of the next observation: Czech respondents failed to assign the highest RP score to the trad-RP speaker. Although the score of 5 might appear to be high, it must be kept in mind that Speaker 6 sits roughly in the middle with the fifth highest score of all. British respondents, on the other hand, unmistakably and unanimously placed Speaker 6 at the very top of the rank.

The comments Czech respondents made about Speaker 6 reveal that the accent is not only 'weird' but also, according to a number of them, regional, too. Crucially though, the accent was ranked fourth in the intelligibility question for Czech respondents. Generally speaking, the accent was not popular with either set of respondents. For British respondents the overwhelming perception of the accent was that of sounding extremely posh.

The comments from both sets of respondents have also shown that while lowered TRAP and short BATH vowels are RP sounds for English respondents, they are not so for their Czech counterparts. Intrusive / $r$ / is most assuredly an RP sound for both sets, as is, in fact, the glottal stop replacing / $t$ / in other than intervocalic positions. $/ \mathrm{t}$ /-glottaling is not treated here for it has been covered extensively elsewhere (cf. Hannisdal 2006).

The last RP sound I want to discuss here in greater detail is the PRICE diphthong. It is one of the most contentious issues in Upton's model of RP and the one for which Wells (2001) finds the least sympathy. This diphthong did draw some comments from British respondents, many of whom noticed the backed first element. The decision as to whether or not this falls within the scope of RP was, however, far from unanimous - about $60 \%$ of those who did comment on it considered $[\Lambda \mathrm{I}]$ to be an RP sound.

Most revealing is the conspicuous lack of any comments on the part of Czech respondents. The reason why they failed to spot any variation here is quite simple: in the Czech phonological system there only are five monophthongal vowels /a/, /e/, /i/, /o/, and /u/ and three diphthongs /au/, /eu/, and /ou/ (Dankovicova 1999: 72). As far as the /a/ vowel is concerned, its realisation varies to a large extent ranging from [a a $\wedge$ ]. The front vowel is common in Bohemia whereas the back one is typical of Moravia. This variation is merely allophonic; as a consequence, Czech learners of English have trouble distinguishing minimal pairs such as fun/fan when these are pronounced by a native speaker of English whose fan vowel is realized as [a] and not as [æ]. It is then far from surprising that Czech respondents did not comment on the PRICE diphthong in the RP Test at all.

\section{Conclusion}

The results of my research seem to suggest that trad-RP is a now such a rarity it has lost its function in the ELT field. It appears to be so obsolete that some Czech respondents mistook it for a regional accent; moreover it is not the most intelligible dialect any more. This might have been brought about by far greater exposure to a higher number of native 
British accents in the past two decades. Learners of English in the Czech Republic rely less and less on textbook CDs and turn to some more natural/authentic sources (TV programmes of all sorts are immensely influential in this respect) when trying to improve their pronunciation.

Upton's model of RP seems highly suitable for Great Britain since it reconciles the two opposing tendencies still present in British society-namely the desire to speak better but, at the same time, to avoid sounding posh and elitist. This is well documented in Beal who comes to the conclusion that 'British society today is every bit as hierarchical as that which spawned the elocution movement of the $18^{\text {th }}$ century, but [...] the models of good pronunciation are no longer the aristocracy but the professional and entrepreneurial classes who can provide employment' (2008: 38). But RP is no longer the automatically preferred accent. Call centres are a case in point - their workers 'avoid both the unfriendly connotations of RP, and the uneducated associations of broad regional accents, and so are acceptable to a wide range of callers' (Beal 2008: 30-1). Surely Upton's model of RP is a step towards a less elitist perception of the accent.

Wells (2001) objects to Upton's model of RP because he sees it as an unnecessary threat to the 'hard-won uniformity' which had been achieved in the transcription of RP. He believes that 'supposed gains did not make up for the sacrifice of an agreed standard' (2001). What should we do, though, if the agreed standard, albeit so laboriously gained, does not reflect the true state of affairs any longer?

Introducing Upton's model to the Czech Republic, however, appears to face many obstacles.

The first and seemingly insuperable obstacle is money. Re-editing and republishing the vast numbers of teaching materials in which pronunciation is discussed would not only be highly impractical but also too expensive.

Secondly, for the reasons mentioned in the Introduction there is not enough support to carry out these changes anyway.

Thirdly, I fear some of the changes would only bring about more confusion for the overwhelming majority of learners (in particular for those who do not study English at university, which is the lowest level where phonetic symbols are dealt with properly in the Czech Republic) for whom phonetic symbols are abstruse and who learn pronunciation by way of imitation rather than by way of pronouncing dictionaries.

Last but not least, RP in the Czech Republic lacks the social and regional connotations it has for native speakers in Great Britain. The roles of RP in the two countries in question are markedly different. What seems necessary in Britain might not be so in the Czech Republic: whilst updating the model in Britain makes sure that the accent is rid of the redolence of social privilege, there is no such problem in the Czech Republic.

It seems, nonetheless, important for Czech learners of English to be aware of the incessant change RP is subject to (it is not a petrified accent, although it is for obvious reasons more resistant to change than other accents). Likewise they should take into account the wealth of connotations this accent is endowed with. They should know that for many people in Britain RP (particularly in the traditional form) is not the preferred accent and the reaction to it may not always be positive. 
RP is the accent used in the Czech Republic as the model accent. This seems extremely unlikely to change in the foreseeable future (if a completely radical change is not undertaken, e.g. replacing RP with the General American accent). I am convinced that it is eminently desirable to resolve the unhappy situation in which the accent often heard from CDs is in certain particulars considerably different from the transcription provided. It is true that CDs often contain recordings with a wide variety of accents; many of them are (slightly) regional and are also different from the phonetic symbols used in the teaching materials. These, however, are not presented as the model students should imitate.

\section{References}

Beal, Joan. 2008. Shamed by Your English? In Joan Beal et al. (eds) Perspectives on Prescriptivism. Bern: Peter Lang, 21-40.

Collins, Beverley et Inger Mees. 2003. Practical Phonetics and Phonology. London: Routledge.

Cruttenden, Alan. 1994. Gimson's Pronunciation of English, $5^{\text {th }}$ ed. London: Arnold.

Dankovicova, Jana. 1999. Czech. In Handbook of the International Phonetic Association, Cambridge University Press, pp. 70-74.

Giles, Howard et al. 1990. The Social Meaning of RP. In Susan Ramsaran (ed) Studies in the Pronunciation of English: A Commemorative Volume in Honour of A. C. Gimson. London: Routledge, 191-211.

Gimson, A. C. 1984. The RP Accent. In Peter Trudgill (ed) Language in the British Isles. Cambridge: Cambridge University Press, 45-54.

Hannisdal, Bente Rebecca. 2006. Variability and change in Received Pronunciation, Ph.D. dissertation. Bergen: University of Bergen.

Honey, John. 1991. Does Accent Matter?. London: Faber and Faber.

Mathesius, Vilem. 1982 [1942]. Jazyk, kultura a slovesnost. Praha: Odeon.

Roach, Peter. 2005. Representing the English Model. In Katarzyna Dzubialska-Kolczyk \& Joanna Przedlacka (eds) English Pronunciation Models: A Changing Scene. Bern: Peter Lang, 393-9.

Upton, Clive. 2000. Maintaining the Standard. In Robert Penhallurick (ed) Debating Dialect: Essays on the Philosophy of Dialect Study. Cardiff: University of Wales Press, 66-83.

Upton, Clive. 2001. Revisiting RP. In Malcolm Jones (ed) Essays in Lore and Language: Presented to John Widdowson on the Occasion of His Retirement. Sheffield: National Centre for English, 351-68.

Upton, Clive, William Kretzschamr and Rafal Konopka. 2003. The Oxford Dictionary of Pronunciation for Current English. Oxford: Oxford University Press.

Upton Clive. 2008. Received Pronunciation. In Clive Upton \& Bernd Kortmann (eds) Varieties of English: The British Isles. New York: Mouton de Gruyter, 237-52.

Wells, J. C. 1982. Accents of English (3 vols). Cambridge: Cambridge University Press. Wells, J. C. 2001. IPA Transcription Systems for English.

http://www.phon.ucl.ac.uk/home/wells/ipa-english-uni.htm [accessed February 2012] 